\title{
Capoeira: ferramenta de inclusão nas aulas de educação física para alunos com necessidades educacionais especiais
}

Capoeira: inclusion tool in physical education classes for students with special educational needs

Capoeira: herramienta de inclusión en las clases de educación física para alumnos con

necesidades educacionales especiales

Christine Avelar Borges Faria ${ }^{1}$, Fabrício Aigner Pinto ${ }^{1 *}$, José Roberto Gonçalves de Abreu ${ }^{1}$

\section{RESUMO}

Objetivo: O objetivo da pesquisa é abranger a capoeira como ferramenta de inclusão nas aulas de educação física para alunos com necessidades educativas especiais, compreendendo os fatores que podem viabilizar este processo. Metodologia: Trata-se de uma pesquisa bibliográfica, pois se baseará, principalmente, de produções técnicas e literárias, artigos, monografias entre outras publicações acerca da temática capoeira, educação física e inclusão. Resultados: Diante do que foi construído, e partindo das limitações encontradas pela falta de produção associada ao tema, pôde-se verificar que a capoeira é uma possibilidade de muitas influências para a pessoa com deficiência. Considerações finais: Concluiu-se que a capoeira pode ser uma ferramenta de inclusão, significativamente possível de ser trabalhada na escola e nas aulas de educação física, pois nela se abrange além da cultura corporal do movimento outros aspectos artísticos, culturais e esportivos que contribuem para esse fim.

Palavras-chave: Capoeira, Educação Física, Inclusão.

\begin{abstract}
Objective: The objective of the research is to cover capoeira as a tool for inclusion in physical education classes for students with special educational needs, understanding the factors that can make this process viable. Methodology: This is a bibliographical research, since it will be based mainly on technical and literary productions, articles, monographs and other publications on the subject of capoeira, physical education and inclusion. Results: Given what was built, and based on the limitations found by the lack of production associated to the theme, it was verified that capoeira is a possibility of many influences for the disabled person. Final considerations: It was concluded that capoeira can be an inclusion tool, significantly possible to be worked in school and physical education classes, because it covers not only the body culture of the movement but also artistic, cultural and sports aspects that contribute to this end.
\end{abstract}

Key words: Capoeira, Physical Education, Inclusion.

\section{RESUMEN}

Objetivo: El objetivo de la investigación es abarcar la capoeira como herramienta de inclusión en las clases de educación física para alumnos con necesidades educativas especiales, comprendiendo los factores que pueden viabilizar este proceso. Metodología: Se trata de una investigación bibliográfica, pues se basará principalmente en producciones técnicas y literarias, artículos, monografías entre otras publicaciones acerca de la temática capoeira, educación física e inclusión. Resultados: Ante lo que fue construido, y partiendo de

${ }^{1}$ Faculdade Vale do Cricaré (FVC), São Mateus-ES. * E-mail: fabricioaigner@hotmail.com 
las limitaciones encontradas por la falta de producción asociada al tema, se pudo verificar que la capoeira es una posibilidad de muchas influencias para la persona con discapacidad. Consideraciones finales: Se concluyó que la capoeira puede ser una herramienta de inclusión, significativamente posible de ser trabajada en la escuela y en las clases de educación física, pues en ella se abarca además de la cultura corporal del movimiento otros aspectos artísticos, culturales y deportivos que contribuyen para ese final.

Palabras clave: Capoeira, Educación Física, Inclusión.

\section{INTRODUÇÃO}

A proposta metodológica de utilizar a capoeira como conteúdo disciplinar em projetos escolares com foco no processo de inclusão, segundo Pimentel (2017) tem gerado alguns conflitos conceituais no que tange a produção teórica e a realidade vivida na prática pelos profissionais da área da Educação Física, isto ocorre em função da falta de qualificação destes profissionais para desenvolverem esta prática no âmbito do que é previsto pelas Diretrizes Educacionais.

Nesta instancia, Pimentel (2017) considera que é preciso ampliar o acesso do profissional da Educação Física a conceitos, métodos e técnicas mais específicas, levando-se em conta que as faculdades deixam muito a desejar sobre o processo metodológico de aprendizagem a partir do uso da capoeira enquanto métodos pedagógicos. Por isto, faz-se necessário conscientizar estes profissionais quanto as contribuições que a capoeira pode propiciar a este processo educacional, uma vez que se constitui uma importante ferramenta para promover a inclusão de alunos com necessidades educacionais especiais.

Estes educadores devem levar em consideração que a capoeira é uma arte brasileira que passou por transformações e evoluiu a um patamar significativo, podendo ser entendida hoje como uma cultura multifacetada, que agrega em seus domínios o esporte, a luta, a dança, o jogo, enfim, atributos interessantes para serem utilizados no âmbito da educação física e no apoio a inclusão (DARIDO, 2013).

Promover a integração social e auxiliar no desenvolvimento das potencialidades dentro das escolas são alguns dos benefícios que a capoeira pode proporcionar aos estudantes, especialmente aqueles com maiores dificuldades de adaptação e socialização, como é o caso dos alunos com necessidades educacionais especiais. Segundo Santos e Luna Filho (2016), a capoeira pode ajudar na promoção de interação social e autonomia dos praticantes. Os autores observam que quando as crianças e jovens praticam este esporte, aprendem a lidar melhor com os desafios que a eles são impostos cotidianamente. Acrescentam que a inclusão destes deve partir do respeito às suas diferenças e combate as injustiças cometidas ao longo dos tempos, como por exemplo, a falta de espaços na sociedade para pessoas com algum tipo de necessidade especial.

Castilha (2012) ressalta que a disciplina de Educação Física, apesar dos avanços percebidos nos últimos tempos, ainda enfrenta grandes barreiras que diminuem as chances de uma educação inclusiva de qualidade. Deste modo, é preciso focar, primeiramente, na questão da formação e qualificação de professores, os quais, desde a graduação, devem ser motivados a diversificarem suas metodologias de ensino, tendo em vista 0 fortalecimento destas práticas no que tange ao processo inclusivo. O importante é, segundo Castilha (2012), encontrar métodos e conteúdos abrangentes, que sejam significativos para a vida do aluno. Partindo-se desta premissa, pode-se dizer que o aluno com necessidades educacionais especiais deve ter aceso a meios que facilitem sua inclusão social, cultural e educacional.

Leme (2017) salienta que os benefícios da capoeira abrangem, não apenas a questão da inclusão social, mas também, a própria saúde mental e física. Sob sua ótica, quando uma criança ou jovem pratica capoeira, a tendência é que tenha uma vida saudável, isto porque contribui significativamente para a elevação do bemestar físico e emocional, produzindo, tanto interna como externamente, boas influencias e energias, através das quais, poderão superar problemas como depressão, baia autoestima e até mesmo problemas físicos como os que se originam no sedentarismo, a exemplo da obesidade. 
Mediante estes enfoques, a presente pesquisa busca questionar a capoeira (conteúdo já consolidado em algumas disciplinas e defendido, por exemplo, nas Leis de Diretrizes e Bases da Educação Nacional (LDB's) e Parâmetros Curriculares Nacionais (PCN's), como ferramenta das aulas de educação física capaz de incluir, integrar e valorizar as diversas potencialidades, às vezes negligenciadas, compreendendo-a através de um fazer pedagógico, no intuito de utilizá-la para emancipar Alunos com Necessidades Educacionais Especiais (ANEE) e auxiliá-los no seu desenvolvimento integral respeitando suas limitações. Uma vez questionada esta possibilidade de usar a capoeira como ferramenta da inclusão, o objetivo da pesquisa é justamente abranger a capoeira como ferramenta de inclusão nas aulas de educação física para alunos com necessidades educativas especiais, compreendendo os fatores que podem viabilizar este processo.

\section{MÉTODOS}

Este artigo trata-se de uma pesquisa bibliográfica, baseado principalmente em produções técnicas e literárias, artigos, monografias entre outras publicações com temáticas pertinentes ao assunto em questão. $O$ artigo faz menção ao contexto histórico da capoeira, descrevendo sucintamente seu percurso inicial até se firmar perante a sociedade e aos órgãos educacionais.

Os artigos foram obtidos através de pesquisas na Base de Dados da Scielo e no Google Acadêmico, utilizando os seguintes descritores: Capoeira, Educação Física, Inclusão, sendo escolhidos os artigos nacionais publicados entre os anos de 2006 e 2018. Os critérios de inclusão foram: artigos publicanos nos últimos doze anos, cujo foco fosse a questão da capoeira enquanto ferramenta pedagógica e inclusiva. Os critérios de exclusão foram: artigos publicados nos anos anteriores a 2006 e que não tratassem especificamente da questão da inclusão educacional e social.

No total, foram obtidos, através da pesquisa, 35 artigos, dos quais, apenas 14 foram utilizados pelo fato de satisfazer os objetivos de pesquisa. utilizou-se ainda como referência, os Parâmetros Curriculares Nacionais Educação Física (1998)

\section{RESULTADOS E DISCUSSÃO}

A capoeira tem sua origem entrelaçada a povos de duas terras distintas e que em determinado momento da história se uniram drasticamente para compor um árduo ofício de lutar pela própria liberdade (KUNZ, 2006).

No início do século XX, a capoeira ainda era associada a marginais. No final do século XX, a história da capoeira volta a tomar suas origens e começa a ter seu devido conhecimento, praticadas por estudantes de cursos nomeados. Pimentel (2017) destaca que, nesta época, a capoeira era praticada em ambientes fechados, momentos em que se criava um sistema de sequência de movimentos de capoeira e vários procedimentos didáticos, acrescenta que a maioria do público que praticava capoeira era os acadêmicos dos cursos de medicina, direito e Engenharia, da antiga universidade da Bahia.

É importante salientar que nos últimos anos a capoeira veio ganhando rumos inesperados. Sua aceitação foi crescendo na sociedade. A discriminação era grande, mas com o tempo foi cedendo lugar a curiosidade, simpatia e respeito. Atualmente é um dos esportes mais praticados no Brasil. Segundo Correia (2012), por meio da capoeira, pode-se ensinar assuntos diversos, dentre eles, a própria cultura afro-brasileira.

O PCN de Educação Física, Brasil (1998, p.71 e 72) estabelece a valorização e participação dos alunos em jogos, lutas e esportes dentro do contexto escolar, sejam de forma recreativa ou competitiva. Declara que se a Educação Física não pode ficar alheia ao que pulsa nas veias dos brasileiros, como é o caso da capoeira e do samba, elementos que formam a cultura popular e que, portanto, devem ser explorados pelas organizações escolares. O referido documento enfatiza ainda sobre a relevância da capoeira para o processo de inclusão de alunos de periferias e da possibilidade renovar as práticas curriculares da escola.

Leme (2017) acredita que os alunos necessitam de experiências corporais significativas e de caráter inclusivo, onde qualquer indivíduo possa, de alguma maneira, transformar, contribuir e se emancipar através dos conteúdos educacionais. Desse modo, na capoeira pode se encontrar uma gama de oportunidades 
pedagógicas. Por exemplo, nela pode-se trabalhar a história, a musicalidade, a ginástica, a luta, a dança, a cultura, a confecção de instrumentos, enfim a capoeira é um conteúdo amplo com possibilidades de ramificações, desmembramentos capazes de atingir interesses, pesquisas e práticas experimentais diversas.

Logo com o mínimo de conhecimento possível e atenção o professor de educação física poderá utilizar a capoeira como ferramenta inclusiva e ministrar uma aula completa e participada por todos, onde cada um tem sua individualidade respeitada e valorizada. Contudo para se aproveitar das possibilidades que a capoeira poderá oferecer seria prudente por parte do professor buscar conhecimento na área, não para se tornar (se não for a intenção) um capoeirista, mas para poder compreender melhor os aspectos que a capoeira está envolvida e utilizá-la em sua totalidade (KUNZ, 2006).

Cabral e Morin (2017) realizaram uma pesquisa bibliográfica sobre o processo de inclusão escolar de alunos com Transtorno do Espectro Autista, identificaram, na literatura, que mesmo com o incentivo do governo, muitos professores sentem grandes dificuldades em deixar de lado o tradicionalismo curricular em função da falta de preparo técnico-profissional para a renovação de suas práticas pedagógicas. Neste sentido, percebe-se que as políticas educacionais devem priorizar, em primeiro lugar, o processo de formação continuada destes professores, dando-Ihes as devidas ferramentas através de capacitações, de modo que possam adquirir novas competências e habilidades para promover a inclusão de alunos, especialmente aqueles que possuem algum tipo de necessidade especial.

Schliemann (2013) realizou uma pesquisa sobre o uso do esporte para promover a inclusão de alunos autistas e identificou que, esportes como o karatê, judô, tae kwon do e capoeira são esportes que conduzem os praticantes a um contexto de dinamismo e muita interatividade, o que pode contribuir para melhorar o desempenho interpessoal dos mesmos, ajudando-os a conquistarem autonomia para tomarem suas próprias decisões, tanto no esporte quanto na vida em sociedade. $O$ autor salienta ainda os benefícios no condicionamento físico dos praticantes deste tipo de esporte.

Sabe-se da preocupação docente quanto ao princípio de inclusão e respeito às diferenças, pois já se entende isto como questão de direitos humanos. Portanto vale qualquer capacitação em áreas de conteúdo específicos para investir em atributos que venha corresponder com às necessidades do alunato em geral $\mathrm{e}$ com as necessidades específicas do aluno com deficiência, transtornos globais do desenvolvimento - TGD e altas habilidades /superdotação - AH /SD, pois apenas a preocupação docente não transforma a dicotomia do discurso e da prática. É preciso investir em ferramentas palpáveis para garantir a igualdade e equidade do ensino (CORREIA, 2012).

A troca de conhecimentos que perpassa o processo de inclusão de alunos deficientes no contexto ensino /aprendizagem, onde o sujeito aprende através do lúdico e do significativo, é determinante para o sucesso da prática docente. Quando se percebe que o conhecimento está sendo mediado e absorvido e o aluno se sente satisfeito e consciente deste processo, o aprendizado se torna mais efetivo e natural (CORREIA, 2012).

Logo, dentro do ambiente escolar, o professor que utiliza o conteúdo da capoeira em suas aulas, para incluir alunos com deficiência, fará com que a turma obtenha um ensinamento criativo, pois através da capoeira poderão (alunos) enriquecer seu conhecimento sobre a arte pesquisada em suas diversas vertentes, utilizando a dança para desenvolver a expressão corporal, a dramatização, algumas valências físicas, utilizando a música para melhorar, trabalhar e executar a oralidade, utilizando a luta, para melhorar a destreza, a disciplina corporal, no que diz respeito ao equilíbrio, a coordenação, a flexibilidade. Utilizando a história, para lembrar de uma época que a capoeira era arma de libertação. Enfim usando das dimensões procedimentais, conceituais e atitudinais encontradas na capoeira para trabalhar com os alunos de maneira diferente e eficaz.

A capoeira tem regras estas podem ser reconstruídas ou adaptadas pelos próprios alunos, como pacto de convivência. Ela também é competitiva, abrindo horizontes para futuros juízes e organizadores de eventos. Castilha (2012) destaca que são várias são as solicitações acerca das valências físicas na capoeira, tanto em movimentos de equilíbrio estático quanto em outros com mobilidade geral (bananeira, aú, compasso de costa, meia lua de compasso, martelo rodado, armada, dentre outros), e esses podem contribuir para tornar mínimo 
a hipotonia peculiar, por exemplo, da pessoa com síndrome de Down. Porém, se o movimento vier atrelado a intencionalidade - caracterizando a psicomotricidade, provavelmente a realização da manobra corporal será desencadeada com eficácia, e nesse caso, desenvolve-se uma ação cognitiva maior.

Neto (2010) cita o exemplo do uso da capoeira para trabalhar a autonomia e socialização de crianças com Síndrome de Down. Segundo ele, a capoeira é uma atividade que proporciona aos seus praticantes uma mobilidade constante que the possibilita um melhor controle, manutenção e aprimoramento das capacidades físicas, fato relevante para qualquer pessoa tendo ou não deficiência. Neto (2010) cita a questão do estímulo ao equilíbrio e o desenvolvimento da consciência corporal, questões estas de grande valia para as aulas Educação Física.

No jogo de perguntas e respostas, "capoeira", a pessoa com deficiência terá necessidade, leal, de analisar a decisão cognitiva mais adequada, para que haja uma melhor utilização do seu acervo motor, diante dos movimentos aprendidos. A comunicação inter-jogadores / inter-pessoal durante o jogo acontece de maneira não-verbal, aonde os corpos emitem os diferentes posicionamentos. Diante do que foi construído, e partindo das limitações encontradas pela falta de produção associada ao tema, pôde-se verificar que a capoeira é uma possibilidade de muitas influências para a pessoa com deficiência. Ao analisar o desenvolvimento psicomotor que ela pode proporcionar para essa população, entendemos que as informações coletadas levam a crer no efeito positivo, pois as aproximações trouxeram que praticante atinge melhora no domínio psicomotor. (NETO, 2010).

Essas explanações servem para argumentar que com um pouco de familiaridade com o conteúdo da capoeira o professor responsável por esta ação encontrará milhares de subsídios que o auxiliarão na iniciativa do processo de inclusão de alunos com necessidades especiais nas aulas de educação física e na capoeira. Contudo para efetivar, integrar e até sustentar o exercício democrático do processo de ensino aprendizagem nas aulas, onde todos são atores deste processo, é preciso mergulhar em uma prática de ensino que possa mobilizar o sujeito a pensar, a descobrir, recriar. E, se a escola é o ambiente ideal para se efetivar a inclusão formando sujeitos na intenção de romper com os muros que o isolam da comunidade, faz-se necessário aprimorar as reflexões pedagógicas e sociais no sentido de possibilitar a autonomia escolar que atualmente com conteúdos minimalistas não ocorre (CHICON JF e RODRIGUES GM, 2013).

Moreira (2007) chama atenção para este aspecto didático da capoeira nos ambientes de ensino. Ressalta a necessidade de conscientizar as novas gerações acerca da importância desta prática, uma vez que, por meio dela, pode-se promover o bem-estar físico e emocional aos praticantes. Por isto, compreende-se que as escolas e organizações sem fins lucrativos devem incentivar a prática da capoeira para a promoção do bem-estar físico e emocional dos alunos, bem como, para promover a inclusão de alunos com necessidades especiais. As atividades que os professores de Educação Física devem desenvolver com os alunos através da capoeira devem explorar questões cognitivas, afetivas, sociais e motores. Matos e Menezes (2012), através de estudos, comprovaram que o uso da capoeira em projetos escolares voltados para a socialização de alunos com necessidades especiais foi bastante útil, principalmente no que se refere a questão da inclusão. Observaram que as crianças com maiores dificuldades em interagir em equipe, através da prática da capoeira, desenvolveram maiores competências para o trabalho em equipe, o que demonstra o quanto estes métodos podem ser favoráveis ao processo de inclusão de alunos com necessidades educacionais especiais, a exemplo dos deficientes visuais, auditivos, autistas, dentre outros tipos de deficiências.

Com base nestas informações, pode-se dizer que a capoeira pode torna-se uma importante aliada na busca pela superação das desigualdades educacionais, culturais e sociais. Leme (2017) destaca que é preciso utilizar metodologias que tragam para a escola a possibilidade de superar as diferenças e dificuldades, dentre elas, as enfrentadas pelos alunos com necessidades educacionais especiais.

\section{CONSIDERAÇÕES FINAIS}

A justificativa de escrever este artigo é a inquietação encontrada na educação básica sobre a inconsistência da efetivação da educação especial integrada ao cotidiano dos alunos. Sabe-se que, de acordo 
com a Lei, a questão de incluir alunos com necessidades educativas especiais é fato promulgado, contudo diferente da confirmação legal de que este grupo de alunos está amparado, encontram-se na prática docente diária, inúmeras dificuldades em se fazer valer a Lei na sua plenitude. O objetivo desta pesquisa se baseou em compreender a capoeira como um conteúdo nas aulas de educação física capaz de incluir alunos com deficiência e auxiliá-los no seu desenvolvimento integral. Para tanto se utilizou de uma pesquisa bibliográfica. No decorrer do trabalho foi percebido que a capoeira é uma ferramenta possível de ser trabalhada na escola e nas aulas de educação física, pois nela se abrange a cultura corporal do movimento de maneira clara e eficiente, onde se observa no processo mediador do conhecimento, que respeitar a escolha dos alunos entre as possibilidades apresentadas referente ao conteúdo trabalhado e o tempo de execução de cada tarefa é possível e eficaz através da capoeira da educação física, pois o tempo não é igual para todos, é aceitar e valorizar o potencial de cada aluno, tendo como indicativo o sujeito da aprendizagem, é abandonar rótulos, classificações, conceitos e pré-conceitos, reconhecendo as diferenças sem privar o direito da aprendizagem. Sendo assim não foi difícil identificar que a capoeira pode ser tratada como uma ferramenta de inclusão nas aulas de educação física, pois em uma única arte pode ser desenvolvidas ao mesmo tempo diversas possibilidades de ensino, oportunizando qualquer aluno a desenvolver ao menos uma delas e se socializar, aprender, inovar e criar com a capoeira e com o planejamento pedagógico do professor. Neste contexto, a atividade pedagógica ultrapassa a intenção de atender aos excluídos, mas sim a todos os educandos em suas diferenças, propondo situações nas quais emerjam as potencialidades de cada um, delineando-se uma nova estrutura de formação. A intervenção gerida pelas múltiplas possibilidades de compartilhamento é desafiadora, mas deve ser considerada como premissa para o fortalecimento das descobertas nas interações com o conteúdo, porque dimensionam as situações vividas na tentativa de superação. Além disso, estar defronte ao multiculturalismo, às desigualdades sociais, às diferenças pessoais, enfim, à diversidade, descrevendo um novo paradigma de pensamento e ação. No entanto novas pesquisas devem ser feitas para que este assunto seja melhor explanado, até de uma maneira mais prática, para que o professor de educação física que não pratica capoeira possa utilizar este conteúdo de maneira mais eficiente em suas aulas. Inovando, já que a capoeira não é tão comum nas aulas de educação física quanto o futebol, por exemplo, e sendo eficiente no processo de ensino aprendizagem e no processo de inclusão da pessoa com deficiência.

\section{REFERÊNCIAS}

1. Brasil. Ministério da Educação. Parâmetros curriculares nacionais: Educação Física/Secretaria de Educação Fundamental. Brasília: MEC /SEF, 1998.

2. CABRAL CS, MARIN AH. Inclusão Escolar de Crianças com Transtorno do Espectro Autista: Uma Revisão Sistemática da Literatura. Educação em Revista, 2017; 6(1).

3. CASCÃO DJ. lê Camará, Arco Íris. Minas Gerais, 2010.

4. CASTILHA FA. Aspectos Pedagógicos da Capoeira. Méritos, Rio Grande do Sul, 2012.

5. CHICON JF, RODRIGUES GM. Educação física e os desafios da inclusão. EDUFES, Espírito Santo, 2013.

6. CORREIA VG. A Comunicação Alternativa e Ampliada no Contexto Escolar: Uma Via de Acesso à Inclusão de Alunos com Paralisia Cerebral. Estudantes com Necessidades Especiais / Singularidades e desafios na prática pedagógica inclusiva, Rio de Janeiro, pg 91-110, 2012.

7. DARIDO SC. Educação Física na Escola: Conteúdos, duas Dimensões e Significados. Universidade Estadual Paulista, São Paulo, s.d. 2013.

8. FALCÃO JLC. O jogo da capoeira em Jogo e a Construção da Práxis Capoeirana. Tese de Doutorado pela Universidade Federal Da Bahia - UFBA, 2006.

9. KUNZ E, et al. Didática da Educação Física 1, 4ª Edição, Unijuí, Rio Grande do Sul, 2006.

10. LEME A. Um estudo dos benefícios físicos e psicológicos da capoeira. INESUL, 2017.

11. MOREIRA R, MOREIRA N. Capoeira: sua origem e sua inserção no contexto escolar. Revista Digital - Buenos Aires - Ano 12 , no114- novembro de 2007

12. NETO JCB. Desenvolvimento Psicomotor Proporcionado Pela Capoeira ao Síndrome de Down- Faculdade Maurício de Nassau, Curso de Bacharelado em Educação Física, Trabalho De Conclusão De Curso, Recife, 2010.

13. PIMENTEL M. Todo brasileiro gosta de capoeira, mas tem um pé atrás com o passado dela. Educação em Revista; 2017; 18(2): $142-148$

14. SANTOS VH, LUNA F, Vicente D. A capoeiracomo instrumento de inclusão social nas aulas de educação física na educação básica. V CONEDU - Congresso de Educação Nacional. Universidade Católica de Pernambuco (UNICAP), 2016.

15. SCHLIEMANN AL. Esporte e Autismo: Estratégias de ensino para inclusão esportiva de crianças com transtornos do espectro autista (TEA). Campinas. Faculdade de Educação Física de Campinas, 2013. 